\title{
Practitioner research: the reflections of a Scot
}

\author{
Peter H. Reid
}

This is an interesting time to be a resident of Scotland with a nationalist government for the first time since the advent of devolution in 1999. Differences between Scotland and other parts of the United Kingdom have, perhaps, become more noticeable, even pronounced, during this period. Currently, there are just two higher education providers in Scotland which cover the library and information discipline: the Department of Information Management, part of Aberdeen Business School at The Robert Gordon University (RGU) and the Department of Computer and Information Sciences at the University of Strathclyde. Both departments offer postgraduate courses within the discipline and base their approaches on producing creative and reflective practitioners who have an understanding both of contemporary issues facing the sector as well as being able to develop and implement research methodologies to investigate these challenges.

Having a strong research pedigree and enabling this to underpin teaching has long been regarded as a mainstay of the library and information science discipline across the whole United Kingdom. Equally important is the maintenance of strong links with the practitioner communities and professional groups. In Scotland this is, perhaps, easier because of our size and because there is almost an "everyone-knows-everyone-else" environment. In many cases, academic research is strongly tied to 'real life' situations on the ground and involves the active participation of professionals in the workplace. In no small measure this approach has been actively encouraged by both CILIP Scotland and the Scottish Library and Information Council (SLIC). The latter administers the Innovation Development Fund (IDF) which prioritises quality, standards and evaluation and service development as well as encouraging active collaboration and co-operation across the sector. Small research projects can (and have been) funded through this initiative.

This approach reinforces the ethos that research within the information discipline in Scotland is not something which is exclusively confined to the olive groves of academe. The philosophy is much more one of practitioner and research rather than practitioner or research. Many practitioners in Scotland recognise that there is a very good, solid case for being involved in research activities both in personal

\section{Author}

Dr Peter Reid is Subject Leader of the Department of Information Management at The Robert Gordon University in Aberdeen. He has been Course Leader for MSc Information and Library Studies for much of the last decade.

Email:p.reid@rgu.ac.uk 
professional terms and also in developing the discipline, solving wider problems and ensuring long term sustainability. Perhaps this ethos emerges strongly out of the much-vaunted Scottish attachment to education and learning and a desire for 'improvement' both personally and to one's service. The message from many practitioners in Scotland is that they know research is good, both for them and for their service. To this end, a number of practitioners are enrolled in part-time higher degree courses (MPhil or PhD or, increasingly, professional doctorates such as RGU's Doctorate of Information Science). These researchers bring with them a wealth of experience generated in the workplace (whether that be in public or private sector) and, as often as not, the enthusiasm of their employers for the subject they are investigating.

Another important facet of academic research is the dissemination of results back to the practitioner community. Both RGU and Strathclyde are actively involved in the dissemination of the results from research projects to practitioner groups. Perhaps one of the most noticeable aspects about the Scottish scene is the extent to which links and partnerships are truly cross-sectoral. There are a number of forums - in addition to the professional body - which bring together practitioners from a wide variety of different environments. Prominent amongst these are Ayrshire Libraries Forum (ALF), Edinburgh Library and Information Services Agency (ELISA), Grampian Information (GI) and Tayside and Fife Library and Information Network (TAFLIN). Often such groups have active participation from academic researchers within the field. Grampian Information which includes members from the public, academic and special sectors (including a significant contingent from the oil and gas industry) has, for example, Professor Rita Marcella, Dean of Aberdeen Business School and a much-respected researcher in the LIS field, as its chair. These bodies organise a wide variety of events from conferences through to training courses and seminars which are forums for the exchange of ideas and for the dissemination of research. Recent speakers have, for example, included Professor Charles Oppenheim and Professor Dorothy Williams.

Increasingly, the National Library of Scotland is becoming actively involved in collaborative research with other parts of the LIS community throughout the country. NLS is keen to contribute to the workings of the regional groups outlined above and the whole focus of the library has shifted in recent years to reinforce its place at the heart of the sector in Scotland. The National Library's five year strategy for 2004-09, entitled Breaking through the walls, emphasised the value of their collections and in widening access, promoting understanding of the collections and supporting the rights of the public to information and knowledge. Breaking through the walls has heralded a shift away from NLS being seen as a "library of last resort" to become a more open and accessible cultural facility. Martyn Wade, the National Librarian, has been keen to foster closer interaction with both The Robert Gordon University and Strathclyde University in this respect. Recently, this has led to collaborative research funding bids by NLS, RGU and Strathclyde, including one focussing on the recentlyacquired John Murray Archive. 
Much valuable research goes on at another level too and the work of students must not be overlooked. Research into local studies provision, for example, led to the development of a continuing professional development course for practitioners. Additionally, it is important to mention the research undertaken by students. The majority of Masters dissertations from either RGU or Strathclyde are based on empirical research examining real-life situations within the library and information sector. Practitioners often play a crucial part in assisting students with their data collection because they recognise that these future librarians are trying to do something worthwhile and may, through their investigations, produce something innovative and revealing. A good recent example of this two-way process is the research undertaken by Neil Paterson, who works at Elmwood College in Fife. Neil undertook the MSc Information and Library Studies by distance learning at The Robert Gordon University. At the dissertation stage he set out to examine and contrast customer service policies and practices of retailers and libraries. His research, focusing on the college library sector, produced a number of very interesting findings and subsequently he has published some of his findings and, perhaps more significantly, has been invited to speak on the subject to a variety of different groups and organisations. Through the rigour of his research and the fact that it was rooted in professional relevance, Neil has started the process of becoming the recognised authority on the subject in Scotland.

Having said all of this, there are still very real challenges which need to be addressed head-on. In particular, both practitioners and academic researchers need to consider how to move collaborative projects off the drawing board and into action. There is a very real enthusiasm for the notion of collaborative research activities and numerous discussions have been held on this. However, moving beyond the preliminary discussion stage is often more difficult.

Sometimes understanding the other side is difficult; sometimes seeing the value of research is hard and sometimes there appears to be a reluctance to face the economic realities of conducting research and to acknowledge that academic departments are not prepared to do things for no return. In addition, it is arguable that much more work requires to be done into the development of meaningful knowledge transfer partnerships between higher education institutions and other bodies. However, there is much that is positive to report and a very real willingness to explore collaboration; the challenge is in moving beyond that. 